\title{
The WHO ultrasonography protocol for assessing hepatic morbidity due to Schistosoma mansoni. acceptance and evolution over 12 years
}

\author{
el Scheich, Tarik ; Holtfreter, Martha C ; Ekamp, Hendrik ; Singh, Daman D ; Mota, Rodrigo ; Hatz,
} Christoph ; Richter, Joachim

\begin{abstract}
The aim of this study is to review the worldwide acceptance of the World Health Organization (WHO) ultrasound protocol for assessing hepatosplenic morbidity due to Schistosoma mansoni since its publication in 2000. A PubMed literature research using the keywords "schistosomiasis and ultrasound," "schistosomiasis and ultrasonography," and "S. mansoni and ultrasound" from 2001 to 2012 was performed. Case reports, reviews, reports on abnormalities due to parasites other than S. mansoni, organ involvement other than the human liver, and reports where ultrasound method was not described were excluded. Six studies were retrieved from other Brazilian sources. Sixty studies on 37,424 patients from 15 countries were analyzed. The WHO protocol was applied with increasing frequency from $43.75 \%$ in the years 2001 to 2004 to $84.61 \%$ in 2009 to 2012 . Results obtained using the pictorial image pattern approach of the protocol are reported in 38/41 studies, whereas measurements of portal branch walls were applied in 19/41 and results reported in 2/41 studies only. The practical usefulness of the pictorial approach of the WHO protocol is confirmed by its wide acceptance. This approach alone proved satisfactory in terms of reproducibility, assessment of evolution of pathology, and comparability between different settings. The measurements of portal branches, also part of the protocol, may be omitted without losing relevant information since results obtained by these measurements are nonspecific. This would save resources by reducing the time required for each examination. It is also more feasible for examiners who are not specialized in medical imaging. As with all protocols, incipient liver fibrosis is difficult to distinguish from normal ultrasound findings of the liver. The ability of this protocol to predict complications in severe cases should be further evaluated in a higher number of patients.
\end{abstract}

DOI: https://doi.org/10.1007/s00436-014-4117-0

Posted at the Zurich Open Repository and Archive, University of Zurich

ZORA URL: https://doi.org/10.5167/uzh-105711

Journal Article

Accepted Version

Originally published at:

el Scheich, Tarik; Holtfreter, Martha C; Ekamp, Hendrik; Singh, Daman D; Mota, Rodrigo; Hatz, Christoph; Richter, Joachim (2014). The WHO ultrasonography protocol for assessing hepatic morbidity due to Schistosoma mansoni. acceptance and evolution over 12 years. Parasitology Research, 113(11):3915-3925.

DOI: https://doi.org/10.1007/s00436-014-4117-0 
The WHO-ultrasonography protocol for assessing morbidity due to Schistosoma haematobium. Acceptance and evolution over 14 years. Systematic review

Robert Akpata, Andreas Neumayr, Martha C. Holtfreter, Ingela Krantz, Daman D. Singh, Rodrigo Mota, Susanne Walter, Christoph Hatz and Joachim Richter Robert Akpata, Hôpital Saint Jean de Dieu, Tanguieta, Benin Robert Akpata, Martha C. Holtfreter, Daman D. Singh, Rodrigo Mota, Joachim Richter $(\bowtie)$ Tropical Medicine Unit, Department for Gastroenterology, Hepatology and Infectious Diseases, Medical Faculty; Heinrich-Heine-University Düsseldorf, Germany.e-mail: Joachim.Richter@med.uni-duesseldorf.de Ingela Krantz, Skaraborg Institute for Research and Development, Skövde, Sweden Andreas Neumayr, Christoph Hatz, Swiss Tropical and Public Health Institute, Basel, Switzerland

Christoph Hatz. Institute for Social and Preventive Medicine, University of Zürich, Switzerland

Susanne Walter, Institute of Biology and Zoomorphology, Faculty of Biology, Heinrich-Heine-University Düsseldorf, Germany

Key words: haematuria, urinary schistosomiasis, urogenital schistosomiasis, genital schistosomiasis, Schistosoma haematobium, ultrasonography, focused ultrasound, inter-observer agreement, bladder cancer, cloudy urine, , residual urine, upper urinary tract obstruction, ureter, calculi 


\section{Abstract}

In 2000, the World Health Organization (WHO) published an ultrasound field protocol for assessing morbidity due to schistosomiasis. The present study aims to review the acceptance of the WHO protocol for Schistosoma (S.) haematobium.

A PubMed literature research using the keywords "ultrasound OR ultrasonography (US) AND schistosomiasis", "US AND S. haematobium.”, "US AND urinary schistosomiasis" from 2001 through 2014 was performed. 38 eligible publications reporting on 17861 patients from 13 endemic and 2 nonendemic countries were analysed. Of these 33 referred to field studies on 17317 patients. The Niamey protocol was applied to $15367 / 17317(88.74 \%)$ patients in 23/33 (69.70\%) of field studies (all studies: 15649/17861 [87.61\%] patients (25/38 [68.42\%] studies). The acceptance of the protocol by single country in field studies varied from 0 to $100 \%$. It varied over time between $55.56 \%(5 / 9)$ in the period from 2001 to 2004 , to $87.50 \%$ (7/8) from 2005 to 2008 , to $62.50 \%$ (5/8) from 2009 to 2011 and $75.00 \%$ (6/8) from 2012 through 2014 (all studies: 50\% [5/10], 88.89\% [8/9], $62.50 \%$ [5/8], 63.64\% [7/11] respectively). The Niamey protocol was applied also in 2/5 hospital studies in 282/544 (51.84\%) patients.

The usefulness of the WHO protocol for $S$. haematobium infections is confirmed by its worldwide acceptance. Some simplifications might facilitate its use also for focused ultrasound examinations performed by less skilled examiners. Organ abnormalities due to schistosomiasis detectable by ultrasonography not yet covered by the WHO protocol should be added to the additional investigations section. 
Introduction

Ultrasonography has been applied to characterize the typical morphologic features of schistosomiasis-induced organ pathology since 1978 (Abdel-Wahab et al. 1978). Ultrasonography compared positively to cystoscopy (Degremont et al. 1985; Burki et al. 1986) and was soon used for morbidity assessment in the field (Doehring et al. 1985; Hatz 2001).

In 1991, a group of experts was convened by the World Health Organization in order to formulate a standardized ultrasonography protocol with the aim to enable the comparison of data obtained in different endemic foci (Cairo Working Group 1991; 1992). This protocol was reviewed and modified during a second meeting which took place in 1996 in Niamey, Niger, in order to revise and improve the WHO-

methodology and published in 2000. (Niamey Working Group 2000; Hatz 2001). The aim of the present study was to analyse the ultrasonographic studies performed since the publication of the Niamey-protocol in terms of world-wide acceptance and the practical experiences of those examiners and study groups who applied this protocol. Furthermore, studies with potential implications for a further amendment of the protocol were evaluated.

\section{Materials and methods}

The literature research process is described in detail in figure 1. Since the present study aims at investigating the acceptance of the protocol, contrary to a classical meta-analysis, every publication regardless of its scientific quality was considered. Exclusion criteria were: letters, reviews, metanalysis, case reports, publications referring to Schistosoma species other than S. haematobium, and localisations other 
than the urinary tract. Further searches were performed for studies on possible additional ultrasonographic investigations.

The main analysis criterion was whether or not the Niamey protocol was applied . Further analysis focused on the populations investigated, e.g. on pre-school-age children, school age children or adults and on the study type (e.g.morbidity assessment prior to interventions, or studies on the evolution after therapy such asregression and subsequent reappearance of lesions in populations continuously exposed to reinfection but not retreated. Moreover, it was analysed if intra- and or inter-observer-agreement of ultrasound results was tested, if possible confounders such as sufficient bladder filling for bladder examination, or voiding prior to examination of the upper urinary tract were mentioned. Further searches examined in how many studies additional investigations such as residual urine or kidney pyelon fibrosis which were proposed in the WHO protocol were performed. Furthermore, searches were performed for other manifestations due to $S$. haematobium detectable by ultrasonography which in future could be proposed as to be included into the additional investigations list of the WHO protocol.

\section{Results}

40 publications on studies performed in 13 endemic and 2 non-endemic countries were eligible. Five publications referred to the same ultrasonographic results of two studies, whereas one publication reported the results of two different studies so that eventually 38 studies were analysed (figure 1) (Campagne et al. 2001; King et al. 2001; Keita et al. 2001; King et al. 2002; Lougue-Sorgho et al. 2002; El Baz et al. 2003; Brouwer et al. 2003; Wamachi et al. 2004; Poda et al. 2004; Garba et al. 2004; Keita et al. 2005; Ouma et al. 2005; Shiff et al. 2006; Koukounari et al. 2006; Nmorsi et al. 2007; Sayed et al. 2007; Nayama et al. 2007; Stothard et al. 2008; Tohon et 
al. 2008; Ramarakoto et al. 2008; Koukounari et al. 2009; Naples et al. 2009; SousaFigueiredo et al. 2009; Ekwunife et al. 2009; Lyons et al. 2009; Koukounari et al. 2010; Bonnard et al. 2011; Qazi et al. 2012; Meurs et al. 2012; Salas-Coronas et al. 2013; Elmadani et al. 2013; Gouvras et al. 2013; Zhong et al. 2013; Strahan et al. 2013; Meurs et al. 2013; Gasmelseed et al. 2014; Njaanake et al. 2014; Ahmed et al. 2014). 17861 patients were examined of whom 17317 were examined in the field. The Niamey protocol was applied to $15367 / 17317$ (88.74\%) patients in $23 / 33$ (69.70\%) field studies (all studies: 15649/17861 [87.61\%] patients (25/38 [68.42\%] studies). The acceptance of the protocol by single country in field studies varied from 0 to $100 \%$ (table 1). It varied over time between $55.56 \%$ (5/9) in the period from 2001 to 2004 , to $87.50 \%$ (7/8) from 2005 to 2008 , to $62.50 \%$ (5/8) from 2009 to 2011 and 75.00\% (6/8) from 2012 through 2014 (all studies: 50\% [5/10], 88.89\% [8/9], 62.50\% [5/8], 63.64\% [7/11] respectively).(fig. 2) The Niamey protocol was applied also in 2/5 hospital studies including 282/544 (51.84\%) patients. (Nayama et al. 2007; SalasCoronas et al. 2013). Other methods applied were either descriptive not following any published protocol or followed the former Cairo protocol (Cairo Working Group 1991; Cairo Working Group 1992).

The Niamey protocol was applied in all studies including pre-school age children (8/8 [100.0\%]), in 16/23 (69.57\%) studies regarding school age children and in 14/20 (70\%) studies on adults ( 7 studies comprised both children and adults. In 2 studies no data on the age of patients were provided) (King et al. 2002; Wamachi et al. 2004; King et al. 2004; Tohon et al. 2008; Meurs et al. 2012; Meurs et al, 2013 Strahan et al. 2013; Njaanake et al. 2014).27/38 (71.05\%) studies on morbidity assessment prior to therapy were performed using the Niamey protocol. $6 / 10(60 \%)$ studies on regression of lesions after therapy referred to the Niamey protocol. (Ouma et al. 2005; Tohon et al. 2008; Ramarakoto et al. 2008; Ekwunife et al. 2009; Qazi et al. 
2012; Strahan et al. 2013). 2/10 studies examined subsequent reappearance, however, none of the two referred to Niamey.

All 4 studies on inter-observer agreement referred to the Niamey protocol (King et al. 2001; Wamachi et al. 2004; Ouma et al. 2005; Bonnard et al. 2001). Since in most of these studies ultrasonography was not the main issue, inter-observer agreement results were not systematically reported on. King et al. (2001) reported that ultrasound results were confirmed by a second blinded examiner, Wamachi et al. (2004) and Ouma et al. (2005) do not specifically report on inter-observer ultrasound data, but compared ultrasonography data obtained by two blinded examiners with results of other investigations thereby suggesting that inter-observer agreement was adequate.

Inter-observer agreement was found excellent in a Senegalese study (Bonnard et al. 2011) where the learning curve of a learning clinician was compared to the results obtained by a teaching radiologist: The frequency of normal ultrasound images was $58 \%$ for the teacher and $59 \%$ for the learner. Mean score of teacher was $0.94 \pm 2.01$ [0-17], and mean score of learner was $1.11 \pm 2.77$ [0-19] without any statistical difference between them $(p=0.08)$. Of the 132 ultrasound examinations, only 12 discrepancies (9\%) were found. Among these 12 discordant ultrasound images, 8 scores had 1 point difference (67\%), 2 had 2 points difference, and 2 were found to have a discrepancy of more than 2 points ( 8 and 10 points). Moreover, in 9 of these discordant ultrasound images, it was the learner who had not seen the lesions seen by the teacher (underestimation) and in 3 cases it was the learner who reported lesions not seen by the teacher. By the third day of the study, after 50 examinations conducted by the learner and teacher, the learner found the same result as the teacher in over $90 \%$ of the cases. Furthermore, the sensitivity/specificity analysis showed that after day 3 the learner screened $100 \%$ of healthy subjects, and within 
two more days of learning, he managed to find all the lesions seen by the teacher without making any mistake. Finally, this learning appeared to persist over time. The other three studies including inter-observer testing reported reliable inter/observer agreement, too. Possible confounders such as insufficient bladder filling during ultrasound examinations or examination of the upper urinary tract before voiding, both possibly leading to an overestimation of organ pathology were mentioned mostly in studies where the Niamey protocol was applied: in $7 / 12$ (58.33\%) of publications mentioning adequate bladder filling (Brouwer et al. 2003; Keita et al. 2005; Shiff et al. 2006; Koukounari et al. 2006; Nmorsi et al. 2007; Ekwunife et al. 2009; Gouvras et al. 2013) and in $7 / 9(77.78 \%)$ of publications mentioning the necessity of voiding before examining the upper urinary tract (Brouwer et al. 2003; Keita et al. 2005; Koukounari et al. 2006; Nmorsi et al. 2007; Ekwunife et al. 2009; Gouvras et al. 2013; Njaanake et al. 2014).

The Niamey-Belo Horizonte protocol proposes additional optional investigations such as the determination of residual urine after voiding and the assessment of kidney pyelon fibrosis. Results on the performance of additional investigations are listed in table 2. Of the 10 publications retrieved by PubMed search only two were eligible (Nmorsi et al. 2007; Watanabe et al. 2012), other results comprised 8 studies (5 before 2000) which do not refer to ultrasonography. Watanabe et al. (2012) compared parasitological data and symptomatology using the International prostate symptoms score (I-PSS) with bladder voiding function as assessed by ultrasound and uroflowmetry. Results of this study suggested that the feeling of incomplete bladder emptying and hesitancy were better indicators for urinary schistosomiasis than the presence of residual urine. Unexpectedly, no significant residual urine post voiding and no decline in urine flow rates were found in $S$. haematobium infected boys. Contrary, volume-corrected maximum and average flow rates in $S$. haematobium 
infected boys were higher than in those not infected. These results suggest that cystitis associated with $S$. haematobium infection causes irritation and hypercontractility of the bladder. The second study also reported that the finding of residual urine after voiding is relatively rare $(27.9 \%)$ as compared to abnormal bladder wall thickening (55.8\%) and abnormal bladder shape (69.8\%). (Nmorsi et al. 2007)

PubMed search did not yield any study on schistosomiasis which would have reported the occurrence of kidney pyelon fibrosis. The non-occurrence of pyelon fibrosis is futher confirmed by a case series and a review on kidney pathology due to schistosomiasis where kidney pyelon fibrosis was also not reported (Barsoum 2003, Shebel et al. 2012). On the other hand, 5 classes of glomerulonephritis have been reported to be related to not only to $S$. haematobium but more frequently to $S$. mansoni: mesangioproliferative; exudative; mesangiocapillary (membranoproliferative); focal segmental sclerosis; and amyloidosis (Barsoum 2003, Duarte et al. 2014).

Searches for ultrasonography AND schistosomiasis or $S$. haematobium AND calcifications retrieved only 7 publications, of which only 3 were published after 2001, only 2 of them were eligible (Nmorsi et al. 2007; Salas-Coronas et al. 2013). These studies confirmed the notion that radiology is more sensitive than ultrasonography for detecting urinary tract calcifications (Burki et al.1986; King 2002).

Although searches for urinary calculi possibly related to urinary schistosomiasis revealed 84 hits, only 12 of them were published since 2001, of which 5 publications were eligible (Holman et al. 2004; Hussein et al. 2006; Abdelrahim et al. 2008; Coulibaly et al. 2011; Khalaf et al. 2012). All studies were hospital based. The different frequency of occurrence of calculi of the urinary tract in schistosomiasis 
patients is likely to be due to the different age as calculi having been only exceptionally seen in children, who are the usual target of field surveys.

After the detailed report on ultrasonographic detection of schistosomiasis-related ureter pathology by Kardorff and Doehring, (2001) 18 further studies (14 eligible) on schistosomiasis were published, mostly referring to schistosomiasis or bladder cancer-induced strictures and urological management of calculi (El Nahas et al. 2003; Neal 2004; Ajit et al. 2005; Hussein et al. 2006; Wong-You-Cheong et al. 2006; Gilligan and Dreicer 2007; Abdelrahim et al. 2008, Abdoulkadir 2009; Abou-Elela et al. 2010; Oranusi et al. 2011; Shebel et al. 2012; Bakari et al. 2012; Vancauwenberghe et al. 2013; Hasegawa et al. 2014). These studies indicate that ultrasonography has a particular potential for the detection of ureter pathology not yet explored by the Niamey protocol.

A particular challenge for ultrasonography is the early detection of schistosomiasisrelated bladder cancer, with special emphasis on its detection during field surveys. 7 ultrasound studies on this issue have been published since 2001, 1 of these being an interesting field study indicating that molecular bladder cancer markers are increased in early urinary schistosomiasis (Shiff et al. 2006; see also Figueiredo et al. 2014b). 2 other studies were hospital observations (Lougue-Sorgho et al. 2002; Salas Coronas et al. 2013), 1 a review (Richter 2003a), 1 reported genetic abnormalities induced by schistosomiasis and 2 referred to exclusion of bladder cancer in schistosomiasis patients.

Attention has increased towards the genital manifestations of schistosomiasis where 53 works have been published since 2001 .

In men some abnormalities possibly indicating schistosomiasis have been described including hyperechogenic spots in the prostate and hydrocele (Richter et al. 2002; Ramarakoto et al. 2008; Figueiredo et al. 2014b). Searches for hydrocele AND 
schistosomiasis yielded 7 hits ( 4 since 2001): 3 publications referred to filariasis, 1 to schistosomiasis (Rambau et al. 2011). Another publication is not listed in PubMed (Richter et al. 2002). The search term combination: ultrasound AND hydrocele AND schistosomiasis yielded no hit.

On the other hand, so far, ultrasound has not been found to be useful to detect specific abnormalities of the female upper reproductive tract (Richter et al. 1995; Ramarakoto et al. 2008). Ultrasound may, however, be helpful in diagnosing complications related to genital schistosomiasis such as sterility, vesico-vaginal fistulae and pregnancy related problems (Richter 2000; Richter et al. 2008; Schanz et al. 2010; Figueiredo et al. 2013, Ben Chetrit et al. 2014; Schleenvoigt et al. 2014). Searches for ultrasound AND schistosomiasis AND pregnancy yielded 9 hits (2 since 2001) which unfortunately were all not eligible. Search for ultrasonography AND schistosomiasis AND placenta yielded 1 hit only where placental schistosomiasis was excluded. The search for placenta AND schistosomiasis yielded 30 hits (15 since 2001). However, placental ultrasonographic abnormalities specifically due to schistosomiasis have not yet been looked for (for more detailed discussion see Schleenvoigt et al. 2014)

Reports on urogenital manifestations due to Schistosoma spp. other than $S$. haematobium were limited to 8 reports on ectopic S. mansoni infections and glomerulonephritis, 6 induced by S. mansoni and 2 reports on kidney abnormalities presumably associated with S. intercalatum since 2001. There was no hit for S. guineensis, S. japonicum, nor for S mekongi.

\section{Discussion}

Ultrasonography is a pivotal method to assess the morbidity of the urinary tract due to schistosomiasis and its complications. At the time when the Niamey protocol was 
proposed the preceding method developed during the WHO meeting in Cairo already had proved useful and reproducible (Hatz 2001) but there is, so far, no experimental proof of the accuracy and usefulness of the protocol as modified in Niamey. Thus, the studies undertaken after the publication of the Niamey protocol constitute the practical evaluation of this modified protocol.

The protocol was accepted by most study groups in the world except some group from Egypt, the Sudan and Niger. This is surprising insofar, that the first WHO protocol had been developed in Cairo (Cairo Working Group 1991) and the second in Niger (Niamey Working Group 2000). Researchers not yet applying the protocol should be encouraged to do so, in order to provide comparable data worldwide. Moreover, although not designed for hospital use, the protocol was found useful also in the hospitals since more than half of the hospitalized patients were also examined using the Niamey protocol. The world-wide adherence to the Niamey protocol for $S$. haematobium by proportion of patients is, thus, comparable to that of the WHO protocol for S. mansoni-related morbidity (El Scheich et al. 2014). Acceptance of the Niamey-protocol proved excellent as compared to another protocol proposed by a WHO expert group i.e. the WHO protocol for the ultrasonographic assessment of echinococcosis (Tamarozzi et al. 2014).

Inter-observer agreement of ultrasonographic findings, using the Niamey protocol was found satisfactory. Possible confounders such as insufficient bladder filling before ultrasound examination and insufficient voiding prior to examination of the upper urinary tract were addressed by the majority of study groups applying the Niamey protocol. The impact of pitfalls on overall results may be minimized further by simplifying the bladder score as well as by keeping the bladder and upper urinary tract scores separate. A simplified bladder scoring was proposed by the group of King and collaborators (King et al. 2001 Wamachi et al. 2004) partly based on a 
former protocol of Medhat et al. 1997) which we re-propose in a slightly modified way:

Grade 0: no abnormality of the urinary bladder-wall which is less then to $5 \mathrm{~mm}$ thick

Grade 1: any area of bladder wall with minor thickening of the bladder wall $5-7 \mathrm{~mm}$

Grade 2: maximum bladder-wall thickening of 8-9 $\mathrm{mm}$

Grade 3: maximum bladder-wall thickening of $10 \mathrm{~mm}$ or more, thus including any polyp, mass or tumor

Another refinement concerning the upper urinary tract could improve its sensitivity (provided the bladder is empty after voiding), i.e. to add the note if there is a fissure of the renal pelvis between $2 \mathrm{~mm}$ and $5 \mathrm{~mm}$.

By these modifications, less skilled examiners might use the protocol more easily. The literature available on the transfer of ultrasonographic skills between a radiologist and a clinician in developing countries is scanty. Recently, in analogy of the use of focused ultrasonography in emergency medicine, it has been proposed to establish training curricula for the ultrasonographic assessment of selected pathologies which can be applied by non-specialised medical personal (Heller et al. 2010). This approach has been successfully applied for the rapid assessment of trauma by clinicians, in obstetrical indications, to assess cystic echinococcosis, obstructive uropathy and to identify tuberculosis in HIV-positive patients in South Africa (Kirkpatrick et al. 2007; Heller et al. 2010; Kimberley et al. 2010; Jang et al., 2010a; Jang et al. 2010b; Del Caprio et al. 2012). The successful transfer of ultrasonographic skills form a radiologist to a clinician sufficient for assessing $S$. haematobium induced urinary tract morbidity has been confirmed in a Senegalese study (Bonnard et al. 2011). As for an on the spot orientation of sufficient bladder filling, it should be reminded that a well-filled bladder changes from an ellipsoid to a 
approximately cubic shape. This might, however, not occur in a schistosomal bladder with a severely thickened wall.

It must be borne in mind, that transabdominal ultrasonography with portable devices for field use is not yet sufficiently sensitive to detect early ulcerative bladder wall abnormalities, independently from which protocol is used. This explains why results obtained by dipsticks are by far more sensitive for detecting urinary schistosomiasis than ultrasonography (Lorgue-Sorgho et al. 2002; van der Werf and de Vlas 2004; Keita et al. 2005; Ahmed et al. 2014). Furthermore ultrasonography is known to be less sensitive than radiology in detecting urinary tract calcifications (Burki et al., 1986; King 2002).

Evolution of schistosomal morbidity after therapy

$6 / 10(60 \%)$ studies on the regression of lesions after therapy referred to the Niamey protocol. (Ouma et al. 2005; Tohon et al. 2008; Ramarakoto et al. 2008; Ekwunife et al. 2009; Qazi et al. 2012; Strahan et al. 2013). Unfortunately, none of the two studies on reappearance of lesions following therapy in re-exposed people referred to the Niamey protocol (Campagne et al. 2001; Garba et al, 2004)

However, since there is a number of studies where evolution of pathology has been assessed using the former Cairo protocol it is likely to be applicable in this respect, too (Hatz et al. 1998; Wagatsuma et al. 1999; Richter 2000, Hatz 2001; Richter 2003a; Richter 2003b). By the modifications of the Niamey protocol as proposed above, the assessment of the regression and subsequent reappearance of lesions in constantly exposed individuals might be evaluated more properly. A cystoscopy study on Brazilian soldiers returning from a peace keeping mission in Mozambique revealed that even after two rounds of adequate praziquantel therapy, 36\% of soldiers who were no more excreting ova in the urine still had viable ova in the 
bladder mucosa (Silva et al. 2006), an important issue also for travel medicine, considering the potential of schistosomiasis to induce bladder cancer (Mostafa, et al. 1999, Amonkar et al. 2001). Unfortunately; this study missed the opportunity to evaluate ultrasonography in this respect. It cannot be overemphasized that a bladder mass or polyp persisting for 6 months or more in spite of antihelminthic therapy is highly suspicious for bladder cancer and that the affected patient must be referred to a adequately equipped hospital for further diagnostic investigations.

Additional investigations

The Niamey-Belo Horizonte protocol also included optional investigations such as the determination of residual urine after voiding and the assessment of kidney pyelon fibrosis. The issue of residual urine after voiding has been addressed by an intriguing study of Watanabe et al. (2012), who compared parasitological findings and symptoms using an International questionnaire developed for prostate disease with results of ultrasomnography and uroflowmetry. Results of this study indicated that the feeling of incomplete bladder emptying and hesitancy were better indicators for urinary schistosomiasis than the presence of residual urine (Watanabe et al. 2012), a result which additionally to the presence of cloudy urine should be taken into account for the questionnaires designed for identifying highly endemic communities for urinary schistosomiasis (Lengeler et al. 1991; Red Urine Study Group, 1995; Wagatsuma et al. 2001; Campagne et al. 2001, Chippaux et al. 2003).

As part of the morbidity due to schistosomiasis detectable by ultrasonography is not yet covered by the WHO protocol it should be included in the additional investigations section since the detection of calculi and calcifications does not cost additional examination time and their presence should be noted. Ureter, at least at their distal end might be investigated systematically for dilatation, wall irregularities, thickenings 
and strictures. A glance to the prostate also in adolescents could reveal early prostate abnormalities (Ramarakoto et al. 2008; Figueiredo et al., 2014b). Depending on the cultural and investigational context, e.g. hospital or health care centre settings, ultrasound examinations of boys and men could include the scrotum to detect genital abnormalities and hydrocele. Although usually attributed to filariasis it is known for a long time that schistosomiasis not unfrequently causes hydrocele also in the absence of filariasis coinfection (Malik and Ibrahim 1982; Richter et al. 2002).

Unfortunately, even using transvaginal probes, specific lesions of the female reproductive tract are difficult to diagnose ultrasonographically. However, complications of genital schistosomiasis, such as ectopic pregnancy possibly associated with intraabdominal bleeding are readily diagnosed ultrasonographically (Richter 2000). The same applies to pregnant women with schistosomiasis, where so far, studies on placenta ultrasound have not been published, although it is known that schistosomiasis also involves the placenta and that the placenta is an organ which is relatively easy to scan (Kimberley et al. 2010; Ben Chetrit et al. 2014; Schleenvoigt et al. 2014). The best documented case series on the pregnancy outcome was published by Ben Chetrit et al. (2014) on 10 pregnant women: the course and outcome of pregnancy in 4 patients who were diagnosed and treated with praziquantel was uneventful whereas 13 babies born to 6 asymptomatic women not diagnosed during pregnancy were significantly smaller as compared with those of the infants of the women who were treated during their pregnancy (median $2.8 \mathrm{vs} 3.5 \mathrm{~kg}$ ).

One baby was born preterm. One infected woman had three miscarriages.

As another possible limitation of ultrasonography one could put forward that urogential tuberculosis may sometimes mimick schistosomiasis. Ultrasonographic differential diagnostic criteria for schistosomiasis are that upper urinary tract 
obstruction is due to bladder and ureter pathology and thus non-specific whereas in tuberculosis hypoechogenic lesions initiate in the kidney parenchyma also affecting the papillae. In doubtful cases, parasitological and bacteriological means are required for differential diagnosis (Das et al. 1992; Tikkakoski et al. 1993; Benchekroun et al. 1997; Hsieh et al. 2006; Singh et al. 2011).

Finally, especially in a Public Health and control context aiming at assessing the morbidity due to $S$. haematobium it must be borne in mind that ultrasound just reveals the tip of the iceberg of $S$. haematobium induced morbidity, since micro- and macrohaematuria, symptomatology and extraurinary localizations may occur also in the absence of ultrasound-detectable lesions (van der Werf and de Vlas 2004). Furthermore, genital and ectopic localizations may occur in the absence of urinary egg excretion. (Poggensee et al. 1998, Ramarakoto et al. 2008; Figueiredo et al. 2014a) and indirect not appreciated morbidity i.e. anemia due to microhaematuria is also not captured by ultrasonography (Tholon et al. 2008).

\section{Conclusions}

In general, the WHO-Niamey-Belo protocol was well accepted since its publication. However, in some regions the protocol is still not applied regularly. Researchers of some highly endemic regions such as Egypt, the Sudan and Niger should be encouraged to use the protocol so that their data can be compared on an international scale. The scoring of bladder wall and upper urinary tract might be slightly modified to simplify its application. The Niamey protocol proved applicable for focused ultrasound assessment by less specialized personnel. A similar protocol is also needed for assessing the morbidity due to $S$. japonicum and $S$. mekongi which should be developed shortly. 


\section{References}

Abdelrahim AF, Abdelmaguid A, Abuzeid H, Amin M, Mousa el-S, Abdelrahim FJ (2008) Rigid ureteroscopy for ureteral stones: factors associated with intraoperative adverse events. Endourol 22(2):277-280

Abdel-Wahab MF, Abdel-Latif Z, El Kady NM, Arafa NM (1978) The use of ultrasonography in the diagnosis of different schistosomal syndromes. Proceedings of the third International Workshop on Diagnostic Ultrasound Imaging, Cairo, Egypt: Al-Ahram Press, $458-463$

Abou-Elela A, Torky M, Salah E, Morsy A, Elsherbiny M. (2010) Inverted ureteral nipple as antireflux technique in surgical management of bilharzial ureteral strictures.

$$
\text { Urology 76(4):983-987 }
$$

Ahmed FO, Hamdan HZ, Abdelgalil HB, Sharfi AA (2014) A comparison between transabdominal ultrasonographic and cystourethroscopy findings in adult Sudanese patients presenting with haematuria. Int Urol Nephrol 6. [Epub ahead of print]

Ajit MK, Groenewald EA, Speakman M. Ann (2005) An unusual presentation of genitourinary schistosomiasis in a Caucasian woman in the UK. R Coll Surg Engl 87(6):481

Amonkar, P, Murali G, Krishnamurthy S (2001) Schistosoma induced squamous cell carcinoma of the bladder. Indian J. Path. Microbiol 44: 363-364

Badmos KB, Popoola AA, Buhari MO, Abdulkadir AY (2009 Ureteric schistosomiasis with obstructive uropathy. J Coll Physicians Surg Pak 19(7):456-458

Bakari AA, Gadam IA, Aliyu S, Suleiman I, Ahidjo AA, Pindiga UH (2012) Use of Mitrofanoff and Yang-Monti techniques as ureteric substitution for severe schistosomal bilateral ureteric stricture: a case report and review of the literature. Niger J Surg 18(1):30-33 
2

3

Barsoum RS (2003) Schistosomiasis and the kidney. Semin Nephrol 23(1):34-41

Benchekroun TS, Kriouil A, Belkacem A, Jorio-Benkhraba M, el Fakir Y, Benhammou M, Outarahout O, el Malki-Tazi A. (1997) [Urogenital tuberculosis in children]. Arch Pediatr 4(9):857-61

Ben-Chetrit E, Lachish T, Mørch K, Atias D, Maguire C, Schwartz E (2014) Schistosomiasis in Pregnant Travelers: A Case Series. J Travel Med. 2014 Oct 13. doi: 10.1111/jtm.12165. [Epub ahead of print]

Bonnard P, Boutouaba S, Diakhate I, Seck M, Dompnier JP, Riveau G (2011) Learning Curve of Vesico-Urinary Ultrasonography in Schistosoma haematobium infection with WHO Practical Guide: A "Simple to Learn" Examination. Am J Trop Med Hyg 85: 1071-1074

Brouwer KC, Ndhlovu PD, Wagatsuma Y, Munatsi A, Shiff CJ (2003) Urinary tract pathology attributed to Schistosoma haematobium: does parasite genetics play a role? Am J Trop Med Hyg 68(4):456-462

Burki A, Tanner M, Burnier E, Schweizer W, Meudt R, Degrémont A (1986) Comparison of ultrasonography, intravenous pyelography and cystoscopy in detection of urinary tract lesions due to Schistosoma haematobium. Acta Trop. 43(2):139-151

Cairo Working Group (1991) Meeting on the use of ultrasound for the assessment of pathology due to schistosomiasis. World Health Organization, WHO Geneva, Switzerland

Cairo Working Group: Hatz C, Jenkins J (1992) The use of diagnostic ultrasound in schistosomiasis-attempts at standardization of methodology. Acta Trop 51: 45-61

Campagne G, Garba A, Barkiré H, Vera C, Sidiki A, Chippaux JP (2001) Continued ultrasonic follow-up of children infected with Schistosoma haematobium after treatment with praziquantel. Trop Med Int Health 6(1):24-30 
Chippaux JP, Campagne G, Garba A, Véra C. (2001) [Significance of rapid evaluation indicators during the monitoring of graduated treatment against Schistosoma haematobium]. [Article in French] Bull Soc Pathol Exot:;94(1):36-41Coulibaly $Y$, Ouattara Z, Togo A, Konate M, Ouattara M, Ouattara K (2011) [Bilharziasis and urinary lithiasis: a study of 23 cases at the Gabriel Toure Hospital] [Article in French]. Mali Med 26(1):26-28. French

Cruz-Martinez R, Figueras F, Jaramillo JJ, Meler E, Méndez A, Hernandez-Andrade E, Gratacos E (2011) Learning curve for Doppler measurement of fetal modified myocardial performance index. Ultrasound Obstet Gynecol 37: 158-162

Das KM, Indudhara R, Vaidyanathan S (1992) Sonographic features of genitourinary tuberculosis. Am J Roentgenol 158(2):327-329

Degremont A, Burki A, Burnier E, Schweizer W, Meudt R, Tanner M (1985) Value of ultrasonography in investigating morbidity due to Schistosoma haematobium infection. Lancet 23(1): 662-665

Del Carpio M, Mercapide CH, Salvitti JC, Uchiumi L, Sustercic J, Panomarenko H, Moguilensky J, Herrero E, Talmon G, Volpe M, Araya D, Mujica G, Calabro A, Mancini S, Chiosso C, Labanchi JL, Saad R, Goblirsch S, Brunetti E, Larrieu E (2012) Early diagnosis, treatment and follow-up of cystic echinococcosis in remote rural areas in Patagonia: impact of ultrasound training of non-specialists. PLoS Negl Trop Dis 6: 1444

Doehring E, Ehrich JH, Reider F, Dittrich M, Schmidt-Ehry G, Brodehl J (1985) Morbidity in urinary schistosomiasis: relation between sonographical lesions and pathological urine findings. Trop Med Parasitol 36(3):145-149

Duarte DB, Vanderlei LA, Bispo RK, Pinheiro ME, Silva Junior GB, Daher EF (2014) Acute kidney injury in Schistosomiasis: A Retrospective Cohort of 60 Patients in Brazil. J Parasitol. 2014 Nov 13. [Epub ahead of print] 
1 Ekwunife CA, Okafor FC, Nwaorgu OC (2009) Ultrasonographic screening of urinary schistosomiasis infected patients in Agulu community, Anambra state, southeast Nigeria. Int Arch Med 2(1):34. doi: 10.1186/1755-7682-2-34

El Baz MA, Morsy TA, El Bandary MM, Motawea SM (2003) Clinical and parasitological studies on the efficacy of Mirazid in treatment of schistosomiasis haematobium in Tatoon, Etsa Center, El Fayoum Governorate. J Egypt Soc Parasitol 33(3):761-776

El-Nahas AR, Shoma AM, El-Baz M (2003) Bilharzial pyelitis: a rare cause of secondary ureteropelvic junction obstruction. J Urol 170(5):1946-1947

Elmadani AE, Hamdoun AO, Monis A, Karamino NE, Gasmelseed N (2013) Ultrasound findings in urinary schistosomaisis infection in school children in the Gezira State Central Sudan. Saudi J Kidney Dis Transpl 24(1):162-167

Figueiredo J, Richter J, Belo S, Grácio MA (2013) Urogenital schistosomiasis presenting genital and urinary tract lesions and abdominal discomfort in a sterile Angolan woman. J Genit Syst Disorders, 2:3 1-4

Figueiredo J, Santos Â, Clemente H, Lourenço A, Costa S, Grácio MA, Belo S (2014a) Schistosomiasis and acute appendicitis]: Acta Med Port 27(3):396-399. Portuguese.

Figueiredo JC, Richter J, Borja N, Balaca A, Costa S, Belo S, Grácio MA (2014b). Prostate adenocarcinoma associated with prostatic infection due to Schistosoma haematobium. Case report and systematic review. Parasitol Res Dec 30 Epub ahead of print]

Garba A, Campagne G, Tassie JM, Barkire A, Vera C, Sellin B, Chippaux JP (2004) Longterm impact of a mass treatment by praziquantel on morbidity due to Schistosoma haematobium in two hyperendemic villages of Niger. Bull Soc Pathol Exot 97(1):7-11

Gasmelseed N, Karamino NE, Abdelwahed MO, Hamdoun AO, Elmadani AE (2014) Genetic diversity of Schistosoma haematobium parasite IS NOT associated with 
severity of disease in an endemic area in Sudan. BMC Infect Dis 14(469). doi: $10.1186 / 1471-2334-14-469$

Gilligan T, Dreicer R (2007) The atypical urothelial cancer patient: management of bladder cancers of non-transitional cell histology and cancers of the ureters and renal pelvis.. Semin Oncol 34(2):145-153

Gouvras AN, Kariuki C, Koukounari A, Norton AJ, Lange CN, Ireri E, Fenwick A, Mkoji GM, Webster JP (2013) The impact of single versus mixed Schistosoma haematobium and S. mansoni infections on morbidity profiles amongst school-children in Taveta, Kenya. Acta Trop 128(2): 309-317

Hasegawa Y, Nishiii M, Masui S, Yoshio Y, Kanda H, Kanai M, Yamada Y, Arima K, Sugimura Y (2014) [Urinary schistosomiasis: report of a case]. Hinyokika Kiyo;60(2):91-94. Japanese

Hatz CF, Vennervald BJ, Nkulila T, Vounatsou P, Kombe Y, Mayombana C, Mshinda H, Tanner M (1998) Evolution of Schistosoma haematobium-related pathology over 24 months after treatment with praziquantel among school children in southeastern Tanzania. Am J Trop Med Hyg. 59(5):775-781

Hatz CF (2001) The use of ultrasound in schistosomiasis. Adv Parasitol 48: 225-284

Heller T, Wallrauch C, Lessells RJ, Goblirsch S, Brunetti E (2010) Short course for focused assessment with sonography for human immunodeficiency virus/tuberculosis: preliminary results in a rural setting in South Africa with high prevalence of human immunodeficiency virus and tuberculosis. Am J Trop Med Hyg 88: 512-515

Holman E, Khan AM, Flasko T, Toth C, Salah MA (2004) Endoscopic management of pediatric urolithiasis in a developing country. Urology. ;63(1):159-162 
1 Hsieh HC, Lu PL, Chen YH, Chen TC, Tsai JJ, Chang K, Chen TP. (2006) Genitourinary tuberculosis in a medical center in southern Taiwan: an eleven-year experience. $J$ Microbiol Immunol Infect 39(5):408-413

Hussein A, Rifaat E, Zaki A, Abol-Nasr M. (2006) Stenting versus non-stenting after noncomplicated ureteroscopic manipulation of stones in bilharzial ureters. Int $\mathrm{J}$ Urol 13(7):886-890

Jang TB, Casey RJ, Dyne P, Kaji A (2010a) The learning curve of resident physicians using emergency ultrasonography for obstructive uropathy. Acad Emerg Med 17: 10241027

Jang TB, Ruggeri W, Dyne P, Kaji AH (2010b) Learning curve of emergency physicians using emergency bedside sonography for symptomatic first-trimester pregnancy. $\mathrm{J}$ Ultrasound Med 29:1423-1428

Kardorff R, Döhring E (2001). [Ultrasound diagnosis of bilharziasis]. Ultraschall Med. 22(3):107-115. Review. German

Keita AD, Dembélé M, Kané M, Fongoro S, Traoré M, Sacko M, Diallo S, Sidibe S, Traoré HA, Doumbo O, Traoré I (2001) Ultrasonographic aspects of urinary schistosomiasis in children of the Dogon plateau and the Niger office; impact of praziquantel treatment. Bull Soc Pathol Exot 94(4):335-338

Keita AD, Sangho H, Sacko M, Diarra Z, Simaga SY, Traore I (2005) Prevalence of schistomasiasis lesions detected by ultrasonography in children in Molodo, Mali. Gastroenterol Clin Biol 29(6-7):652-655

Khalaf I, Shokeir A, Shalaby $M(2012)$ Urologic complications of genitourinary schistosomiasis. World J Urol 30(1):31-38 
1 Kimberly HH, Murray A, Mennicke M, Liteplo A, Lew J, Bohan JS, Tyer-Viola L, Ahn R, Burke T, Noble VE (2010) Focused maternal ultrasound by midwives in rural Zambia. Ultrasound Med Biol 36: 1267-1272

King, CH (2002) Ultrasound Monitoring of Structural Urinary Tract Disease in Schistosoma haematobium infection. Mem Inst Os Cruz 97(Suppl. I): 149-152

King $\mathrm{CH}$, Muchiri EM, Mungai $\mathrm{P}$, Ouma JH, Kadzo H, Magak P, Koech DK (2002) Randomized comparison of low-dose versus standard-dose praziquantel therapy in treatment of urinary tract morbidity due to Schistosoma haematobium infection. Am J Trop Med Hyg 66(6):725-730

King $\mathrm{CH}$, Blanton RE, Muchiri EM, Ouma JH, Kariuki HC, Mungai $\mathrm{P}$, Magak $\mathrm{P}$, Kadzo $\mathrm{H}$, Ireri E, Koech DK (2004) Low heritable component of risk for infection intensity and infection-associated disease in urinary schistosomiasis among Wadigo village populations in Coast Province, Kenya. Am J Trop Med Hyg 70(1):57-62

King CL, Malhotra I, Mungai P, Wamachi A, Kioko J, Muchiri E, Ouma JH (2001) Schistosoma haematobium-induced urinary tract morbidity correlates with increased tumor necrosis factor-alpha and diminished interleukin-10 production. J Infect Dis 184(9):1176-1182

Kirkpatrick AW (2007) Clinician-performed focused sonography for the resuscitation of trauma. Crit Care Med 35: 162-172

Koukounari A, Sacko M, Keita AD, Gabrielli AF, Landouré A, Dembelé R, Clements AC, Whawell S, Donnelly CA, Fenwick A, Traoré M, Webster JP (2006) Assessment of ultrasound morbidity indicators of schistosomiasis in the context of large-scale programs illustrated with experiences from Malian children. Am J Trop Med Hyg 75(6):1042-1052 
1 Koukounari A, Webster JP, Donnelly CA, Bray BC, Naples J, Bosompem K, Shiff C (2009) Sensitivities and specificities of diagnostic tests and infection prevalence of Schistosoma haematobium estimated from data on adults in villages northwest of Accra, Ghana. Am J Trop Med Hyg 80(3):435-441

Koukounari A, Donnelly CA, Sacko M, Keita AD, Landouré A, Dembelé R, Bosqué-Oliva E, Gabrielli AF, Gouvras A, Traoré M, Fenwick A, Webster JP (2010) The impact of single versus mixed schistosome species infections on liver, spleen and bladder morbidity within Malian children pre- and post-praziquantel treatment. BMC Infect Dis. Jul 29;10:227. doi: 10.1186/1471-2334-10-227

Lengeler C, Kilima P, Mshinda H, Morona D, Hatz C, Tanner M (1991) Rapid, low.cost, twostep method to screen for urinary schistosomiasis at the district level: the Kilosa experience. Bull WHO 69:179-189

Lougue-Sorgho LC, Cisse R, Kagone M, Bamouni YA, Tapsoba TL, Sanou A (2002) Radiography and ultrasonography in the management of bladder tumors: 71 cases at the National Hospital Center of Yalgado Ouedraogo (Burkina Faso)]. Bull Soc Pathol Exot 95(4):244-247

Lyons B, Stothard R, Rollinson D, Khamis S, Simai KA, Hunter PR. (2009) A comparison of urinary tract pathology and morbidity in adult populations from endemic and nonendemic zones for urinary schistosomiasis on Unguja Island, Zanzibar. BMC Infect Dis 9:189. doi: 10.1186/1471-2334-9-189

Malik MO, Ibrahim A (1982) Scrotal swellings in Sudanese patients: a surgical pathology study. Int Surg. 67(4 Suppl):513-515.Medhat A, Zarzour A, Nafeh M, et al. (1997) Evaluation of an ultrasonographic score for urinary bladder morbidity in Schistosoma haematobium infection. Am J Trop Med Hyg 57:16-19

Meurs L, Mbow M, Boon N, van den Broeck F, Vereecken K, Dièye TN, Abatih E, Huyse T, Mboup S, Polman K (2013) Micro-geographical heterogeneity in Schistosoma 
mansoni and S. haematobium infection and morbidity in a co-endemic community in northern Senegal. PLoS Negl Trop Dis 7(12):e2608. doi:

10.1371/journal.pntd.0002608

Meurs L, Mbow M, Vereecken K, Menten J, Mboup S, Polman K (2012) Bladder morbidity and hepatic fibrosis in mixed Schistosoma haematobium and S. mansoni Infections: a population-wide study in Northern Senegal. PLoS Negl Trop Dis 6(9):e1829. doi: 10.1371/journal.pntd.0001829

Mostafa MH, Sheweita SA, O'Connor PJ (1999). Relationship between schistosomiasis and bladder cancer. Clin Microbiol Rev 12(1):97-111

Naples J, Isharwal S, Shiff CJ, Bosompem KM, Veltri RW.(2009) Clinical utility of squamous and transitional nuclear structure alterations induced by Schistosoma haematobium in chronically infected adults with bladder damage verified by ultrasound in Ghana. Anal Quant Cytol Histol 31(3):143-152

Nayama M, Garba A, Boulama-Jackou ML, Touré A, Idi N, Garba M, Nouhou H, Decanter C (2007) Uro-genital schistosomiasis with S. haematobium and infertility in Niger. Prospective study of 109 cases. Mali Med 22(3):15-21. French

Neal PM (2004) Schistosomiasis--an unusual cause of ureteral obstruction: a case history and perspective. Clin Med Res 2(4):216-227

Niamey Working Group: Richter J, Hatz C, Campagne G, Jenkins J (2000) Ultrasound in Schistosomiasis. A practical guide to the standardized use of ultrasonography for the assessment of schistosomiasis-related morbidity. World Health Organization, World Health Organization / TDR / STR/ SCH / WHO-document: 1-51. www.who.int/tdr/publications/publications/ultrasound.htm; last accessed January 25, 2015 
1 Njaanake KH, Simonsen PE, Vennervald BJ, Mukoko DA, Reimert CM, Gachuhi K, Jaoko WG, Estambale BB (2014) Urinary cytokines in Schistosoma haematobium-infected schoolchildren from Tana Delta District of Kenya. BMC Infect Dis 14(501) doi: $10.1186 / 1471-2334-14-501$

Nmorsi OP, Ukwandu NC, Ogoinja S, Blackie HO, Odike MA (2007) Urinary tract pathology in Schistosoma haematobium infected rural Nigerians. Southeast Asian J Trop Med Public Health 38(1):32-37

Oranusi CK, Nwofor A, Onyiaorah IV, Ukah CO. (2011) Schistosomal stricture of the ureterdiagnostic dilemma. Niger J Clin Pract 14(4):495-498

Ouma JH, King CH, Muchiri EM, Mungai P, Koech DK, Ireri E, Magak P, Kadzo H (2005) Late benefits 10-18 years after drug therapy for infection with Schistosoma haematobium in Kwale District, Coast Province, Kenya. Am J Trop Med Hyg 73(2):359-364

Poda JN, Traoré A, Sondo BK (2004) Schistosomiasis endemic in Burkina Faso. Bull Soc Pathol Exot 97(1):47-52

Poggensee G, Sikelu M, Saría M, Richter J, Krantz I, Feldmeier H (1998) Schistosomiasis of the lower reproductive tract without egg excretion in urine. Am J Trop Med Hyg 59(9): 782-783

Qazi A, Stahlschmidt J, Subramaniam R (2012) Bladder morbidity and hepatic fibrosis in mixed Schistosoma haematobium and S. mansoni Infections: a population-wide study in Northern Senegal. J Pediatr Urol 8(4): 438-41. doi: 10.1016/j.jpurol.2011.11.008

Ramarakoto CE, Leutscher PD, van Dam G, Christensen NO (2008) Ultrasonographical findings in the urogenital organs in women and men infected with Schistosoma haematobium in northern Madagascar. Trans R Soc Trop Med Hyg 102(8):767-773 
1 Rambau PF, Chandika A, Chalya PL, Jackson K (2011) Scrotal swelling and testicular atrophy due to schistosomiasis in a 9-year-old boy: a case report. Case Rep Infect Dis. 2011:787961.

Red Urine Study Group (1995) Identification of high-risk communities for schistosomiasis in Africa. A multicountry study. WHO TDR document, World Health Organization Geneva, Switzerland: 1-83

Richter J, Poggensee G, Helling-Giese G, Kjetland E, Chitsulo L, Koumenda N, Gundersen S, Krantz I, Feldmeier H (1995) Transabdominal ultrasound for the diagnosis of genital schistosomiasis in women with Schistosoma haematobium infection: a preliminary report. Trans Roy Soc Trop Med Hyg 89:500-501

Richter J, Wagatsuma Y, Aryeetey M, Feldmeier H (1996) Sonographic screening for urinary tract abnormalities in patients with Schistosoma haematobium infection: pitfalls in examining pregnant women. Bull World Health Org 74(2):217-221

Richter J (2000) Evolution of schistosomiasis-induced pathology after therapy and interruption of exposure to schistosomes: a review of ultrasonographic studies. Acta Tropica 77: 111-131

Richter J, Stegemann U, Häussinger D (2002) Hydrocele in a young boy with Schistosoma mansoni infection. Brit J Urology 89:1-2

Richter J (2003a) The impact of chemotherapy on the morbidity due to schistosomiasis. Acta Trop 86: 161-183

Richter J, Hatz C, Häussinger D (2003b). Ultrasound in tropical and parasitic diseases. Lancet 362: 900-902

Richter J, Lux J, Reinecke P, Müller-Mattheis V (2008) Of flukes and fistulae. Lancet 371 : 1308 
Salas-Coronas J, Vázquez-Villegas J, Villarejo-Ordóñez A, Sánchez-Sánchez JC, EspadaChavarría J, Soriano-Pérez MJ, Cabeza-Barrera MI, Cabezas-Fernández MT (2013) Radiological findings in patients with imported schistosomiasis. Enferm Infecc Microbiol Clin 31(4):205-209

Sayed HA, Hammam O, Sabry H, Akl M, Amin T, El Lithy T, Roshdy M, El Ganzoury H (2007) Epidemiologic approach for early detection and control of renal and urinary tract diseases in rural populations. J Egypt Soc Parasitol 37(1):313-328

Schanz, A, Richter J. Beyer I, Baldus SE, Hess AP, Kruessel JSJ (2010) Genital schistosomiasis as a cause of female sterility and acute abdomen. Fertility \& Sterility ;93(6):2075.e7-9

Schleenvoigt BT, Gajda M, Baier M, Groten T, Oppel-Heuchel H, Grimm MO, Pfister W, Richter J, Pletz MW (2014) Placental Schistosoma haematobium infection in a German returnee from Malawi. Infection 42(6):1061-1064

Shebel HM, Elsayes KM, Abou El Atta HM, Elguindy YM, El-Diasty TA (2012) Genitourinary schistosomiasis: life cycle and radiologic-pathologic findings. Radiographics. ;32(4):1031-1046

Shiff C, Veltri R, Naples J, Quartey J, Otchere J, Anyan W, Marlow C, Wiredu E, Adjei A, Brakohiapa E, Bosompem K (2006) Ultrasound verification of bladder damage is associated with known biomarkers of bladder cancer in adults chronically infected with Schistosoma haematobium in Ghana. Trans R Soc Trop Med Hyg 100:847-854

Silva IM, Thiengo R, Conceição MJ, Rey L, Pereira Filho E, Ribeiro PC (2006) Cystoscopy in the diagnosis and follow-up of urinary schistosomiasis in Brazilian soldiers returning from Mozambique, Africa. Rev Inst Med Trop S Paulo 48(1):39-42

Singh DD, Vogel M, Müller-Stöver I, el Scheich T, Winzer M, Göbels S, Hüttig F, Heinrich S, Mackenzie C, Jensen B, Reuter S, Häussinger D, Richter J (2011) TB or nor TB? 
Difficulties in the diagnosis of tuberculosis in HIV-negative immigrants to Germany. Eur J Med Res 16(9):381-384

Sousa-Figueiredo JC, Basáñez MG, Khamis IS, Garba A, Rollinson D, Stothard JR (2009) Measuring morbidity associated with urinary schistosomiasis: assessing levels of excreted urine albumin and urinary tract pathologies. PLoS Negl Trop Dis 3(10):e526. doi: 10.1371/journal.pntd.0000526

Stothard JR, Sousa-Figueiredo JC, Simba Khamis I, Garba A, Rollinson D (2009) Urinary schistosomiasis-associated morbidity in schoolchildren detected with urine albuminto-creatinine ratio (UACR) reagent strips. J Pediatr Urol 5(4):287-291

Strahan R, McAdam D, Schneider ME (2013) Sonographic response in the liver and urinary bladder of children 14 months after treatment for schistosomiasis. Trop Doct 43(2):71-74

Tikkakoski T, Karstrup S, Lohela P, Hulkko A, Apaja-Sarkkinen M. (1993) Tuberculosis of the lower genitourinary tract: ultrasonography as an aid to diagnosis and treatment. J Clin Ultrasound 21(4):269-271

Tohon ZB, Mainassara HB, Garba A, Mahamane AE, Bosqué-Oliva E, Ibrahim ML, Duchemin JB, Chanteau S, Boisier P (2008) Controlling schistosomiasis: significant decrease of anaemia prevalence one year after a single dose of praziquantel in Nigerian schoolchildren. PLoS Negl Trop Dis 2(5):e241. doi: 10.1371/journal.pntd.0000241

Van der Werf MJ, de Vlas SJ (2004) Diagnosis of urinary schistosomiasis: a novel approach to compare bladder pathology measured by ultrasound and three methods for hematuria detection. Am J Trop Med Hyg 71(1):98-106

Vancauwenberghe T, Oyaert M, Termote JL, Mulkens T, Bellinck P (2013) Ureteral obstruction caused by schistosomiasis..JBR-BTR; 96(5):292-294 
Wagatsuma Y, Aryeetey ME, Sack DA, Morrow RH, Hatz C, Kojima S. (1999) Resolution and resurgence of Schistosoma haematobium-induced pathology after communitybased chemotherapy in Ghana, as detected by ultrasound. J Infect Dis 179(6):15151522.

Wagatsuma Y, Aryeetey ME, Nkrumah FK, Sack DA, Kojima S (2003) Highly symptomaware children were heavily infected with urinary schistosomiasis in southern Ghana. Cent Afr J Med 49(1-2):16-19

Wamachi AN, Mayadev JS, Mungai PL, Magak PL, Ouma JH, Magambo JK, Muchiri EM, Koech DK, King CH, King CL (2004) Increased ratio of tumor necrosis factor-alpha to interleukin-10 production is associated with Schistosoma haematobium-induced urinary-tract morbidity. J Infect Dis 190(11):2020-2030

Watanabe K, Muhoho ND, Mutua WR, Kiliku FM, Awazawa T, Moji K, Aoki Y (2011) Assessment of voiding function in inhabitants infected with Schistosoma haematobium. J Trop Pediatr 57(4):263-268

Wong-You-Cheong JJ, Woodward PJ, Manning MA, Davis CJ (2006) From the archives of the AFIP: Inflammatory and nonneoplastic bladder masses: radiologic-pathologic correlation. Radiographics 26(6):1847-1868

Zhong X, Isharwal S, Naples JM, Shiff C, Veltri RW, Shao C, Bosompem KM, Sidransky D, Hoque MO (2013) Hypermethylation of genes detected in urine from Ghanaian adults with bladder pathology associated with Schistosoma haematobium infection. PLoS One 8(3):e59089. doi: 10.1371/journal.pone.0059089 
Table 1 Ultrasound studies on urinary tract abnormalities due to $S$. haematobium 2001-2014

Countries No. of studies No. of patients Niamey/field US \%Niamey/field st.

$\begin{array}{lrrrr}\text { Mali } & 4 & 6.424 & 3 / 4 & 75.00 \\ \text { Kenya } & 7 & 4.502 & 7 / 7 & 100.00 \\ \text { Nigeria } & 3 & 1.745 & 3 / 3 & 100.00 \\ \text { Senegal } & 3 & 881 & 3 / 3 & 100.00 \\ \text { Egypt } & 2 & 795 & 0 / 2 & 0.00 \\ \text { Zambia } & 1 & 763 & 1 / 1 & 100.00 \\ \text { Ghana } & 3 & 655 & 3 / 3 & 100.00 \\ \text { Niger } & 3 & 518 & 1 * / 2 & 0.00 \\ \text { Tanzania } & 4 & 500 & 1 / 4 & 25.00 \\ \text { Sudan } & 3 & 384 & 0 / 2 & 0.00 \\ \text { Zimbabwe } & 1 & 222 & 1 / 1 & 100.00 \\ \text { Madagascar } & 1 & 221 & 1 / 1 & 100.00 \\ \text { Burkina Faso } & 1 & 71 & 0 / 0 & \text { n.a. }{ }^{*} \\ \text { Imported cases: } & & & 1 / 0 & \text { n.a. }{ }^{*} \\ \text { Spain } & 1 & 178 & 0 / 0 & \text { n.a. }{ }^{*} \\ \text { UK } & 1 & 2 & & \end{array}$

Total

38

17.861

$23 / 33^{*}$

$69.70^{*}$

${ }^{*}$ n.a.= not applicable, because these studies were hospital studies; all studies $25 / 38=65.79 \%$ 
Table 2 Results of Searches for Additional Ultrasound (US) Investigations for exploring S. haematobium-related organ abnormalities

no. of hits / no. hits from 2001 to 2014

\section{Additional Investigations proposed in the WHO-protocol:}

Residual urine AND schistosomiasis

10/5, eligible: 2

US AND schistosomiasis AND kidney fibrosis

0

US AND urinary schisto AND kidney pyelon fibrosis

0

Kidney fibrosis AND schistosomiasis

29/7, eligible: 0

US AND calcifications AND schistosomiasis

$7 / 3$, eligible: 2

US AND S. haematobium AND calcifications

$4 / 1$

\section{Additional Investigations not yet covered by the WHO-protocol:}

schistosomiasis AND ureter

US AND ureter AND schistosomiasis

Calculi, and urinary schistosomiasis

US AND calculi AND schistosomiasis

US AND bladder cancer AND urinary schistosomiasis

US AND urogenital schistosomiasis

US AND genitourinary schistosomiasis

US AND genital schistosomiasis*
168/19, eligible: 15

$11 / 5$

84/12, eligible: 5

$6 / 1$

20/7

156/52

$88 / 33$

$17 / 8$

\footnotetext{
* 4 studies were retrieved by other searches than by PubMed
} 


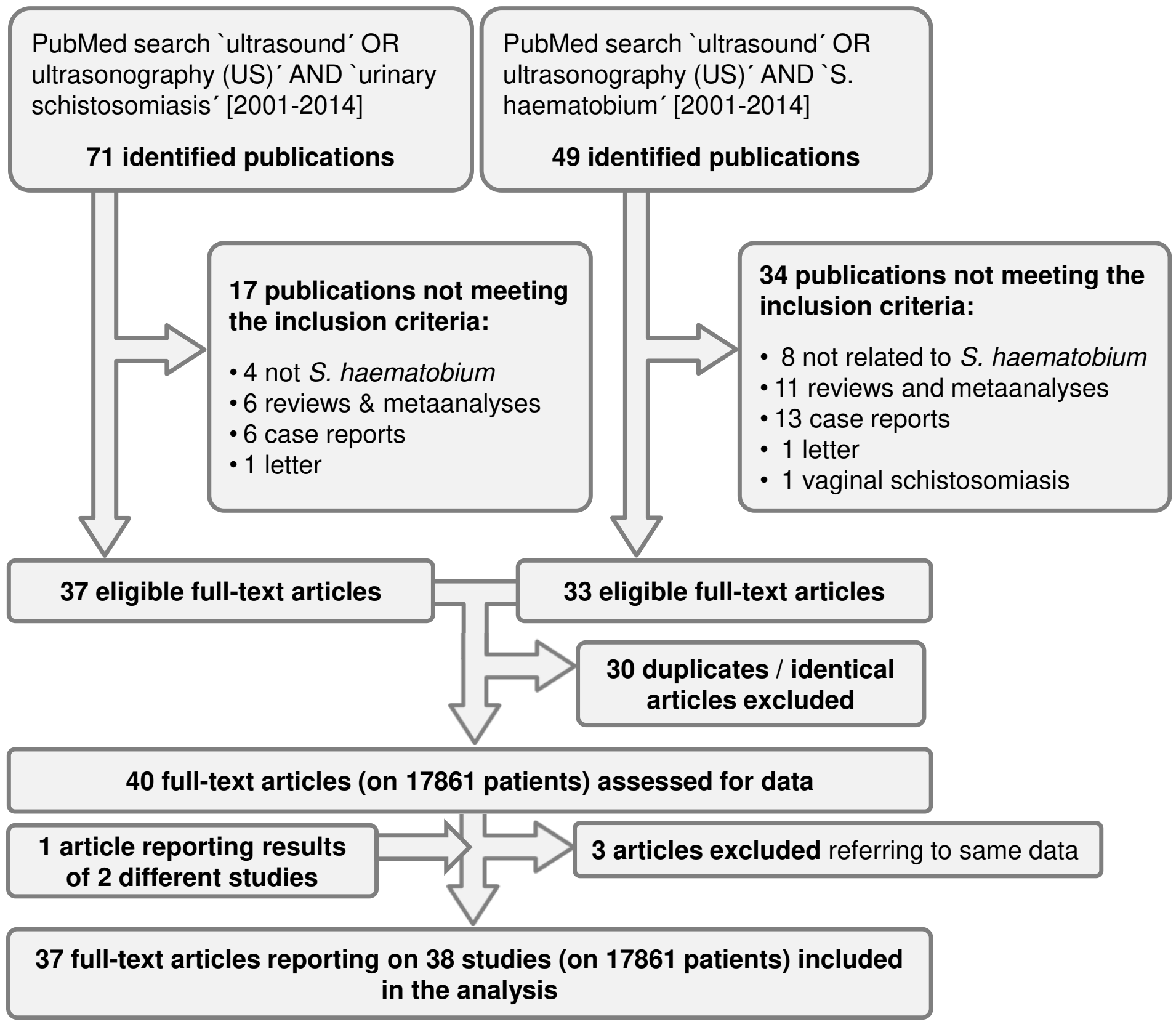




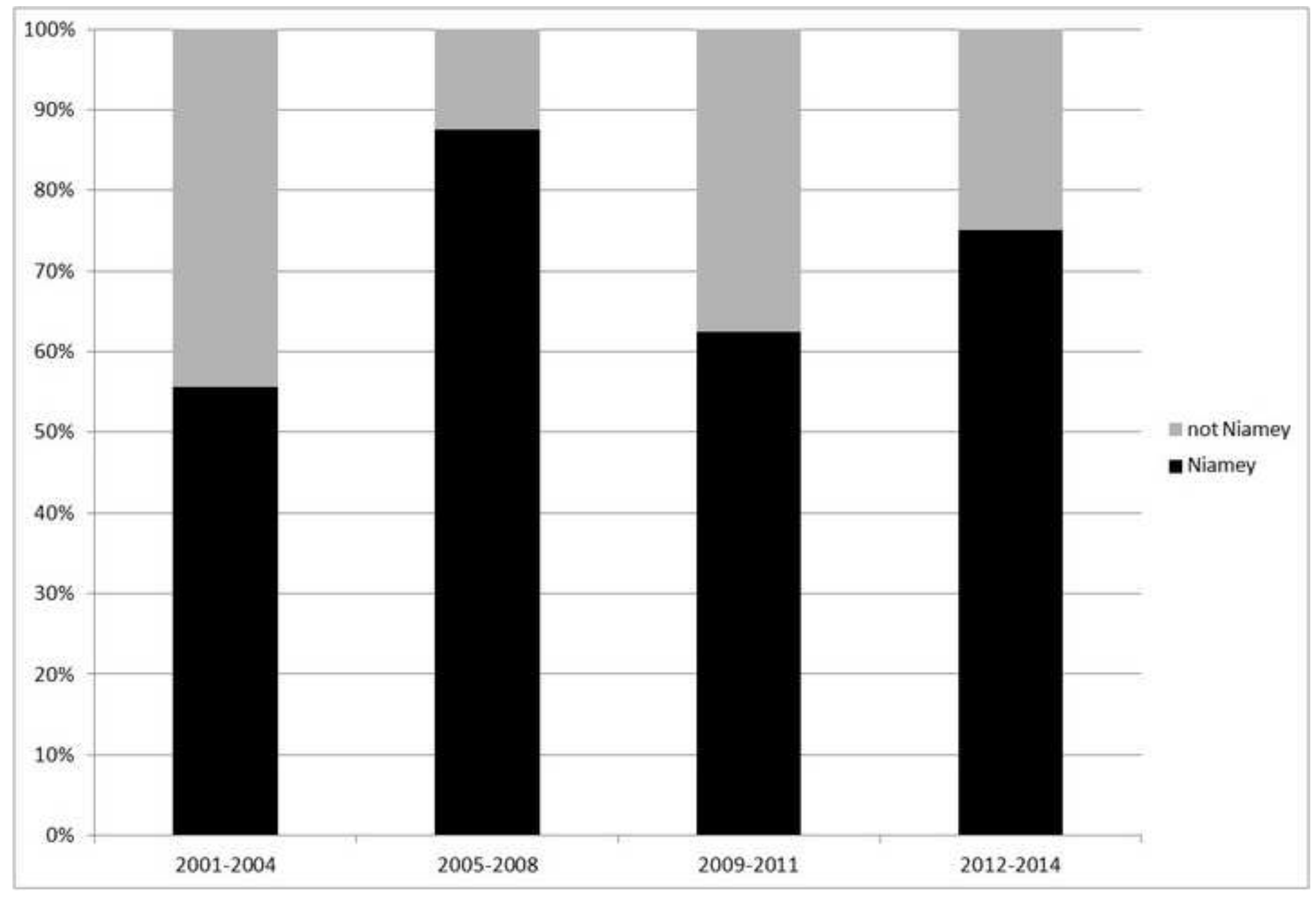

